\title{
PREVALENCE AND CORRELATES OF SUICIDAL BEHAVIOR AMONG NEW SOLDIERS IN THE U.S. ARMY: RESULTS FROM THE ARMY STUDY TO ASSESS RISK AND RESILIENCE IN SERVICEMEMBERS (ARMY STARRS)
}

\author{
Robert J. Ursano, M.D. ${ }^{1, *}$, Steven G. Heeringa, Ph.D. ${ }^{2}$, Murray B. Stein, M.D., M.P.H. ${ }^{3,4,5}$, \\ Sonia Jain, Ph.D. ${ }^{4}$, Rema Raman, Ph.D. ${ }^{4,6}$, Xiaoying Sun, M.S. ${ }^{4}$, Wai Tat Chiu, A.M. ${ }^{7}$, Lisa J. \\ Colpe, Ph.D., M.P.H. ${ }^{8}$, Carol S. Fullerton, Ph.D. ${ }^{1}$, Stephen E. Gilman, Sc.D. ${ }^{9}$, Irving Hwang, \\ M.A. ${ }^{7}$, James A. Naifeh, Ph.D. ${ }^{1}$, Matthew K. Nock, Ph.D. ${ }^{10}$, Anthony J. Rosellini, Ph.D. ${ }^{7}$, \\ Nancy A. Sampson, B.A. ${ }^{7}$, Michael Schoenbaum, Ph.D. ${ }^{8}$, Alan M. Zaslavsky, Ph.D. ${ }^{7}$, and \\ Ronald C. Kessler, Ph.D. ${ }^{7}$
}

${ }^{1}$ Center for the Study of Traumatic Stress, Department of Psychiatry, Uniformed Services University of the Health Sciences, Bethesda, Maryland ${ }^{2}$ Institute for Social Research, University of Michigan, Ann Arbor, Michigan ${ }^{3}$ Department of Psychiatry, University of California San Diego, La Jolla, California ${ }^{4}$ Department of Family and Preventive Medicine, University of California San Diego, La Jolla, California ${ }^{5}$ VA San Diego Healthcare System, San Diego, California ${ }^{6}$ Department of Neurosciences, University of California San Diego, La Jolla, California ${ }^{7}$ Department of Health Care Policy, Harvard Medical School, Boston, Massachusetts ${ }^{8}$ National Institute of Mental Health, Bethesda, Maryland ${ }^{9}$ Departments of Social and Behavioral Sciences, and Epidemiology, Harvard School of Public Health, Boston, Maryland ${ }^{10}$ Department of Psychology, Harvard College, Cambridge, Massachusetts

\section{Abstract \\ Background-The prevalence of suicide among U.S. Army soldiers has risen dramatically in recent years. Prior studies suggest that most soldiers with suicidal behaviors (i.e., ideation, plans, and attempts) had first onsets prior to enlistment. However, those data are based on retrospective self-reports of soldiers later in their Army careers. Unbiased examination of this issue requires investigation of suicidality among new soldiers.}

\begin{abstract}
Method-The New Soldier Study (NSS) of the Army Study to Assess Risk and Resilience in Servicemembers (Army STARRS) used fully structured self-administered measures to estimate preenlistment histories of suicide ideation, plans, and attempts among new soldiers reporting for Basic Combat Training in 2011-2012. Survival models examined sociodemographic correlates of each suicidal outcome.
\end{abstract}

\footnotetext{
${ }^{*}$ Correspondence to: Robert J. Ursano, Center for the Study of Traumatic Stress, Department of Psychiatry, Uniformed Services University of the Health Sciences, 4301 Jones Bridge Road, Bethesda, MD 20814. robert.ursano@usuhs.edu.

Conflict of interest. Dr. Kessler worked as a consultant for Hoffman-LaRoche, Inc., Johnson \& Johnson Wellness and Prevention, and Sanofi-Aventis Groupe; and served on advisory boards for Mensante Corporation, Plus One Health Management, Lake Nona Institute, and U.S. Preventive Medicine. He owns 25\% share in DataStat, Inc. The remaining authors report nothing to disclose.
} 
Results-Lifetime prevalence estimates of preenlistment suicide ideation, plans, and attempts were 14.1, 2.3, and 1.9\%, respectively. Most reported onsets of suicide plans and attempts (73.3$81.5 \%$ ) occurred within the first year after onset of ideation. Odds of these lifetime suicidal behaviors among new soldiers were positively, but weakly associated with being female, unmarried, religion other than Protestant or Catholic, and a race/ethnicity other than non-Hispanic White, non-Hispanic Black, or Hispanic.

Conclusions_-Lifetime prevalence estimates of suicidal behaviors among new soldiers are consistent with retrospective reports of preenlistment prevalence obtained from soldiers later in their Army careers. Given that prior suicidal behaviors are among the strongest predictors of later suicides, consideration should be given to developing methods of obtaining valid reports of preenlistment suicidality from new soldiers to facilitate targeting of preventive interventions.

\section{Keywords}

military personnel; prevalence; suicide; suicide ideation; suicide attempt

\section{INTRODUCTION}

There has been a dramatic increase in the suicide rate among Army soldiers over the past decade, with the Army suicide rate now surpassing the suicide rate in the general population. ${ }^{[1]}$ As such, there is a need to improve our ability to predict suicide risk among soldiers so that targeted preventive interventions can be developed, evaluated, and, when shown to be successful, implemented. The most recent epidemiological study of suicidal behaviors among U.S. Army soldiers was based on the All Army Study (AAS) survey in the Army Study to Assess Risk and Resilience in Servicemembers (Army STARRS), a large epidemiological-neurobiological study of Army suicides and their correlates. ${ }^{[2]}$ The AAS assessed lifetime history of suicidality in a representative sample of soldiers exclusive of those in Basic Combat Training (BCT). Considerably higher prevalence of suicide ideation (13.9\%), suicide plans (5.3\%), and suicide attempts (2.4\%) was found among AAS respondents than sociodemographically matched civilians. Importantly, for purposes of intervention planning, the majority of AAS respondents with a history of suicide ideation (58.2\%) reported that their suicidal thoughts began prior to enlistment, whereas only slightly lower proportions of AAS respondents with suicide plans (52.9\%) and attempts (47.0\%) reported preenlistment onsets. ${ }^{[3]}$

Given that suicidal behaviors are among the strongest and most consistent predictors of completed suicides, ${ }^{[4]}$ and given that several interventions have been shown to be effective in decreasing the persistence of suicidal behaviors, ${ }^{[5,6]}$ the AAS evidence regarding preenlistment onset of most Army suicidality raises the question whether it would be valuable to screen new soldiers for a preenlistment history of suicidality in order to help target preventive interventions early in the Army career. Although questions have been raised about the value of such screening due to concerns about the validity of self-reports, barriers to effective interventions, and confidentiality, ${ }^{[7,8]}$ strong evidence that a high proportion of suicidal soldiers has preenlistment onsets might shift the balance of thinking about these critiques. However, an important limitation of the AAS has to be addressed before any such reconsideration is warranted: that age-of-onset (AOO) in the AAS was 
assessed using long-term retrospective reports made by soldiers at various stages of their Army career. This raises the possibility that the AAS estimate of high preenlistment onset of soldier suicidality might be in error, making it difficult to establish definitively from the AAS data the extent to which soldier suicidality emerged for the first time prior to enlistment. Here, we address this limitation by examining lifetime prevalence of preenlistment suicidality in a large, representative sample of new soldiers survyed within 2 days of reporting for BCT. These data come from the New Soldier Study (NSS) component of Army STARRS. We report on NSS estimates of preenlistment lifetime prevalence, AOO, and sociodemographic correlates of suicide ideation, plans, and attempts among new soldiers.

\section{MATERIALS AND METHODS}

\section{SAMPLE}

The NSS surveyed new soldiers about to begin BCT at Fort Benning, GA; Fort Jackson, SC; and Fort Leonard Wood, MO between April 2011 and November 2012. Data were collected in the days just before BCT when new soldiers were being processed in Reception Battalion (e.g., getting physical examinations; receiving their uniforms). Sample sizes were proportional to the size of the cohorts at each installation. Weekly samples of 200-300 soldiers were selected at each installation to attend a study overview and informed consent presentation for the study. Army STARRS staff worked closely with Army coordinators to guarantee that these samples were representative of all new soldiers in each weekly cohort. The overview and informed consent presentation explained study purposes, confidentiality, emphasized that participation was voluntary, and answered all questions before seeking written informed consent to (1) complete a self-administered questionnaire (SAQ), (2) allow linkage of their Army and Department of Defense (DoD) administrative records to their SAQ responses, and (3) be contacted regarding future data collections. Identity information (e.g., name, SSN) was collected from consenting respondents and kept in a separate secure file. These recruitment, consent, and data protection procedures were approved by the Human Subjects Committees of the Uniformed Services University of the Health Sciences for the Henry M. Jackson Foundation (the primary grantee), the Institute for Social Research at the University of Michigan (the organization collecting the data), and all other collaborating organizations.

A total of 38,507 NSS respondents completed the SAQ between April 2011 and November 2012 and consented for administrative data linkage. The sample was further restricted to 38,237 respondents in order to exclude new soldiers who were older than 33 at enlistment for purposes of examining survival distributions. All new soldiers selected to attend the informed consent session did so, virtually all (99.9\%) provided consent, and most (93.7\%) completed the full SAQ. Incomplete surveys were primarily due to time constraints (e.g., cohorts arriving late or having to leave early; certain respondents being unable to fully complete the surveys during the allotted time). Most soldiers who completed the survey also provided consent for and were successfully linked to their administrative records $(77.0 \%)$. All analyses reported here utilize a combined analysis weight that both adjusts for differential administrative record linkage consent among soldiers who completed the survey

Depress Anxiety. Author manuscript; available in PMC 2016 November 17. 
and includes a poststratification of these consent weights to known demographic and service characteristics of the population of new soldiers attending BCT during the study period. A detailed description of NSS clustering and weighting is available elsewhere. ${ }^{[9]}$

\section{MEASURES}

Suicidal Behavior-Suicidal behaviors were assessed using a modified self-report/ baseline version of the Columbia Suicidal Severity Rating Scale (C-SSRS) ${ }^{[10]}$ that inquired about the lifetime occurrence and AOO separately for suicide ideation ("Did you ever in your life have thoughts of killing yourself?" or "Did you ever wish you were dead or would go to sleep and never wake up?"), and among respondents who reported lifetime ideation, suicide plans ("Did you ever have any intention to act [on these thoughts/on that wish]?" and, if so, "Did you ever think about how you might kill yourself [e.g., taking pills, shooting yourself] or work out a plan of how to kill yourself?") and attempts ("Did you ever make a suicide attempt [i.e., purposefully hurt yourself with at least some intention to die]?"). Retrospective AOO was reported categorically for onsets under 18 years of age with "less than 13" being the earliest. All respondents reporting less than 13 were recoded to have an $\mathrm{AOO}$ of 12.

Sociodemographics-Sociodemographic variables assessed in the NSS survey and included here are as follows: time-varying person- year and education and time invariant sex, race-ethnicity, religion, marital status, parental education, and nativity. Education was coded as time-varying in the person-year survival models based on assumed normative educational transitions. Marital status was coded as time-invariant due to the fact that the NSS neglected to obtain information on the timing of marriage or marital disruption. We also controlled for Army component (Regular Army, National Guard, or Army Reserve).

\section{ANALYSIS METHODS}

Retrospective AOO reports for suicide ideation, plans, and attempts were analyzed using the two-part actuarial method to estimate survival curves, a method differing from the KaplanMeier ${ }^{[11]}$ method by using a more accurate way of estimating onsets within a given year. ${ }^{[12]}$ Discrete time survival analysis, with person-year as the unit of analysis and a logistic link function, ${ }^{[13]}$ was used to examine associations of sociodemographics with onset of suicidal behaviors. The person-year file was constrained to be in the range 12-33 years of age because only a handful of respondents reported onset of suicidality prior to age 12 and fewer than $1 \%$ of new soldiers were older than 33 at the time of enlistment. Strength of associations was evaluated with Cramer's V $\left(\phi_{\mathrm{c}}\right)$. Survival coefficients were exponentiated to create odds ratios (ORs) with $95 \%$ confidence intervals. ${ }^{[11,12]}$ As the NSS data were both clustered and weighted, the design-based Taylor series linearization method was used to estimate standard errors. ${ }^{[14]}$ Multivariate significance was examined using design-based Wald $\chi^{2}$ tests. Statistical analyses were conducted using the software $\mathrm{R}$, version 3.0.2, ${ }^{[15]}$ with the R library survey ${ }^{[16,17]}$ to estimate the discrete time survival analysis models. 


\section{RESULTS}

\section{LIFETIME PREVALENCE OF SUICIDAL BEHAVIOR}

Lifetime prevalence estimates of preenlistment suicide ideation, plans, and attempts in the NSS were 14.1, 2.3, and 1.9\%, respectively (Table 1). Less than one-in-five new soldiers with a history of suicide ideation developed a suicide plan prior to enlistment $(16.6 \%)$ or made a suicide attempt prior to enlistment (13.0\%), while nearly half (44.2\%) of all preenlistment ideators with a plan went on to make a preenlistment attempt compared to only $7.4 \%$ of ideators without a plan.

\section{AOO AND PROBABILITY OF TRANSITIONS ACROSS SUICIDAL BEHAVIORS}

Cumulative AOO curves show that the lifetime prevalence of preenlistment suicidal behaviors increased dramatically between 12 and 20 years of age (Fig. 1). The overlap among curves indicates that transitions from ideation to plan and attempt typically were quite rapid. Indeed, speed of transition curves (Fig. 2) show that $81.5 \%$ of the transitions from ideation to plans and $80.4 \%$ of the transitions from ideation to unplanned attempts occurred within 1 year of onset of ideation, whereas $73.3 \%$ of the transitions from plans to attempts occurred within 1 year of onset of plans.

\section{SOCIODEMOGRAPHIC AND PRIOR SUICIDALITY PREDICTORS OF SUICIDAL BEHAVIOR}

Distributions of the sociodemographic variables considered here are reported elsewhere. ${ }^{[18]}$ Using multivariate survival models and controlling for the age patterns documented in Figs. 1 and 2, we examined the associations of sociodemographic variables at the time of enlistment with preenlistment suicidal behavior (Table 2).

Gender-Female new soldiers had significantly elevated odds of preenlistment suicide ideation $(\mathrm{OR}=1.4)$, plans $(\mathrm{OR}=1.3)$, and attempts $(\mathrm{OR}=1.6)$, but the magnitudes of these associations were all small in substantive terms $\left(\phi_{\mathrm{c}}=.01-.04\right)$. Gender difference in preenlistment transitions from ideation to either plans or attempts among ideators were insignificant. These results suggest that the higher odds of plans and attempts among female than male new soldiers are due largely to elevated odds of ideation.

Marital Status-New soldiers who were unmarried at the time of enlistment (i.e., never married, separated, widowed, or divorced) had statistically significant elevated odds of preenlistment suicidality (ideation, plans, and attempts; ORs $=1.7-2.1$ ), but the magnitude of these associations was consistently small in substantive terms $\left(\phi_{\mathrm{c}}=.02-.05\right)$. Being unmarried was not significantly associated with plans or attempts among ideators.

Race/Ethnicity-Non-Hispanic Black new soldiers had significantly lower odds of preenlistment suicide ideation, plans, and attempts (ORs $=0.6-0.7)$ than those who were non-Hispanic White, whereas new soldiers who identified themselves as having "Other" race-ethnicity had significantly higher odds of suicide ideation and plans (ORs $=1.2-1.4)$ than non-Hispanic Whites, although the substantive strength of these associations was consistently modest $\left(\phi_{\mathrm{c}}=.01-.06\right)$. Race/ethnicity was unrelated to conditional risk of suicide plans and attempts among ideators. 
Religion-Relative to new soldiers who were Protestant, Catholics had lower odds of preenlistment suicide ideation and plans (ORs $=0.7-0.8$ ), whereas those with "other" religion or "no" religion had significantly higher odds of preenlistment suicide ideation and plans (ORs $=1.1-1.5)$, and, in the case of those endorsing "other" religion, higher odds of preenlistment suicide attempt $(\mathrm{OR}=2.0)$ than Protestants along with higher odds of unplanned attempt among ideators $(\mathrm{OR}=2.1)$. These associations were consistently small, though, in substantive terms $\left(\phi_{\mathrm{c}}=.02-.06\right)$. There were no significant associations of religion with conditional risks of suicide plans or attempts among ideators with a plan.

Education-New soldiers who attended at least some college prior to enlistment had lower odds than other new soldiers at comparable ages of all the preenlistment suicidal behaviors beginning with the time they entered college. This was significantly so for suicide plans and plans among ideators $(\mathrm{OR}=0.2)$. Those with less than a high school diploma reported significantly lower odds of making a suicide plan $(\mathrm{OR}=0.5)$ than high school graduates, but significantly higher odds of sui cide attempts among ideators without a plan $(\mathrm{OR}=2.3)$. During the years when they were students, new soldiers had significantly lower odds of ideation and plans (ORs $=0.5-0.8$ ), but higher odds of plans among ideators and attempts among ideators without a plan (ORs $=1.8-2.8)$ than nonstudents who received a high school diploma. The substantive strength of the associations between education and suicidality, though, was consistently modest $\left(\phi_{\mathrm{c}}=.02-.07\right)$. Parental education, in comparison, was for the most part not significantly related to history of respondent suicidal behaviors, although new soldiers whose parents were college graduates when the soldiers were not had significantly lower odds than other new soldiers of unplanned attempts among ideators (OR $=0.6)$.

Nativity-New soldiers not born in the United States had significantly lower odds of preenlistment suicide ideation $(\mathrm{ORs}=0.8)$ than those born in the United States. However, nativity was not significantly associated with conditional risk of plans or attempts among ideators.

Service Component-Relative to those in the Regular Army, new soldiers in the Army National Guard had increased odds of preenlistment suicide ideation and plans (ORs $=1.1-$ 1.3), whereas those in the Army Reserve had higher odds of ideation ( $\mathrm{OR}=1.2)$, although these associations were very small in substantive terms. There were no associations between service component and history of plans or attempts among ideators.

AOO of Prior Suicidal Behaviors-Among new soldiers with a history of preenlistment suicide ideation, those with an $\mathrm{AOO}$ of 13 years and later were significantly less likely than those with preteen onset to transition to a preenlistment suicide plan (ORs $=0.5-0.7)$ and to make a preenlistment unplanned attempt (ORs $=0.5-0.9$; results not shown).

\section{DISCUSSION}

These results should be viewed in the context of two important limitations. First, some respondents may have failed to report a history of suicidal behaviors due to factors such as embarrassment or fear of negative career consequences. This means that the NSS estimates 
of preenlistment prevalence of suicidality might be conservative. This conclusion is consistent with the results of previous methodological studies showing that potentially embarrassing behaviors are often underreported ${ }^{[19]}$ and that retrospective reports produce more conservative prevalence estimates than prospective designs. ${ }^{[20]}$ Second, we assessed only a limited set of correlates of suicidal behaviors. However, we did this merely to investigate broad sociodemographic distributions. Based on these analyses, we found that sociodemographic correlates of preenlistment suicidality are modest in substantive terms. This means that these behaviors are widely distributed by sociodemographic status among new soldiers. Prior studies, in comparison, have shown that a wide range of factors beyond sociodemographics are associated with elevated risk of suicidal behavior. ${ }^{[1]}$ We made no attempt to investigate this wider range of predictors here, but will do so in future analyses of the NSS data.

In the context of these limitations, the most important finding of the study from the perspective of the concern raised in the introduction is that the prevalence estimates of preenlistment suicidality in the NSS replicate those obtained from retrospective reports in the earlier STARRS report from the AAS. This consistency adds support to the suggestion in the AAS that the majority of soldiers with suicide ideation and plans had first onsets prior to enlistment. The NSS analyses also replicate prior AAS findings that most transitions from suicide ideation and plans to attempts occur within the first year after the onset of ideation and that sociodemographic associations with suicidality among soldiers are relatively weak. The replication of these results across different samples of soldiers is encouraging and suggests that the observed patterns are robust. Each of these current findings warrants some commentary.

This study revealed that $14.1 \%$ of new Army soldiers report a preenlistment history of suicide ideation, $2.3 \%$ report having made a suicide plan, and $1.9 \%$ report a prior history of suicide attempt. These estimates are in line with those reported in an earlier study of suicidal behavior across all nondeployed active duty soldiers. ${ }^{[3]}$ Notably, the rates of preenlistment suicide plans and attempts are slightly lower than those reported in a recent study of suicidal outcomes in a nationally representative civilian sample weighted to be sociodemographically comparable to the U.S. Army, ${ }^{[21]}$ but somewhat higher in the case of suicide ideation. Taken together, this suggests that new soldiers have higher rates of suicide ideation than their matched civilian peers, but lower rates of progressing to suicidal plans or attempts. This latter finding may be because those who progress to suicidal planning and attempting are more likely to be identified and rejected for service. It is less clear why the rate of suicide ideation reported here is higher than would be expected based on preenlistment reports from the Army STARRS AAS study of active duty soldiers (8.1\%) as well as from the aforementioned civilian study (11.7\%). This could represent a cohort effect in which newer recruits are coming into the service with higher rates of suicide ideation than earlier cohorts. This is something that may be important for the Army to monitor over time.

On a related note, these results further support the idea that some portion of soldiers has a history of suicidal thoughts and behaviors which is detectable upon entry in the Army. Notably, however, these data were obtained for research purposes with the promise of confidentiality. Currently, potential recruits who report prior suicidal behavior in 
preenlistment evaluations would have to receive a special waiver in order to join the Army. Given that context, it is unlikely that more exhaustive preenlistment clinical screening efforts could identify many of these cases, as reporting such behaviors would be against the interests of recruits who want to join the Army. Whether or not new soldiers would admit prior suicidal behaviors at the beginning of BCT, in comparison, is less clear, as suicidal behavior is not disqualifying for continued military service even though it is disqualifying for enlistment. Although compelling arguments have been made against universal screening of new soldiers, ${ }^{[7,8]}$ it is important to recognize that prior suicidal behavior is among the best predictors of future suicidal behavior. ${ }^{[4]}$ As a result, identifying new soldiers with prior suicidal behavior could represent an important means of targeting preventive interventions. A potential way forward might be to screen for a history of such behaviors among new soldiers after making it clear that reports of prior suicidal behavior would lead to evaluation for preventive intervention and in some cases to treatment rather than to being screened out of service.

Data from the NSS also showed that the risk of first onset of suicidal behavior increases dramatically during adolescence (i.e., from 12 to 20 years) and that the transition from suicide ideation and plans to first suicide attempt happens quickly, most often within first year after onset of ideation/plans. These results are consistent with prior findings from representative studies in the general population ${ }^{[22-24]}$ and among servicemembers ${ }^{[3]}$ and suggest that many new soldiers with prior suicide ideation who will ever make a suicide attempt already did so by the time that they started BCT. The extent to which new soldiers with prior suicide ideation ( $>1$ year prior to BCT) —who did not make a prior suicide attempt - might still benefit from outreach and prevention services, remains a question for future study.

This study also identified several significant correlates of suicidal behavior among new soldiers. The elevated odds of nonlethal suicidal behavior among those who are female or unmarried is well-replicated in the literature and the current study adds further to the data in support of these associations. ${ }^{[25]}$ Lower cognitive ability has been linked with suicide among servicemembers in prior studies. ${ }^{[26,27]}$ In the current study, we found that new soldiers with less than a high school diploma actually had lower odds of suicide ideation and plans overall, but higher odds of acting on their suicidal thoughts - especially in the case of unplanned suicide attempts. It may be that some third variable, such as impulsiveness, is associated with failure to obtain a high school diploma and also increases the likelihood of acting on suicidal thoughts. We are unable to draw any firm conclusions regarding the causal dynamics underlying this association, and it remains an intriguing direction for future study.

Another interesting finding in this study was the association between religion and suicidal behavior. New soldiers endorsing no religion or one other than Catholic or Protestant had elevated odds of suicide ideation and plans, as well as higher odds of attempt among those endorsing another religion. The inverse association between religiosity and suicidal behavior has been documented in dozens of studies. ${ }^{[28]}$ What is unclear in the current study, however, is the reason for the higher odds of suicidal outcomes among those endorsing a religion other than Protestant or Catholic. Given that the majority of new soldiers who endorse a religion identify as Protestant (54.8\%) or Catholic $(17.2 \%),{ }^{[18]}$ and that attendance at 
religious services has been shown to be protective against suicide, ${ }^{[29]}$ it may be that those not participating in the dominant religions are at elevated risk because of the lack of access to the positive aspects of such participation (e.g., supportive social networks) or are less likely to approach their local religious leader (e.g., Army chaplain) for help when in psychological distress.

\section{Acknowledgments}

Army STARRS was sponsored by the Department of the Army and funded under co-operative agreement number U01MH087981 with the U.S. Department of Health and Human Services, National Institutes of Health, National Institute of Mental Health (NIH/NIMH). The contents are solely the responsibility of the authors and do not necessarily represent the views of the Department of Health and Human Services, NIMH, the Department of the Army, or the Department of Defense.

The Army STARRS Team consists of Co-Principal Investigators: Robert J. Ursano, M.D. (Uniformed Services University of the Health Sciences) and Murray B. Stein, M.D., M.P.H. (University of California San Diego and VA San Diego Healthcare System).

Site Principal Investigators include Steven Heeringa, Ph.D. (University of Michigan) and Ronald C. Kessler, Ph.D. (Harvard Medical School); NIMH collaborating scientists are Lisa J. Colpe, Ph.D., M.P.H. and Michael Schoenbaum, Ph.D.; Army liaisons/consultants are COL Steven Cersovsky, M.D., M.P.H. (USAPHC) and Kenneth Cox, M.D., M.P.H. (USAPHC). Other team members include Pablo A. Aliaga, M.A. (Uniformed Services University of the Health Sciences); COL David M. Benedek, M.D. (Uniformed Services University of the Health Sciences); Susan Borja, Ph.D. (National Institute of Mental Health); Gregory G. Brown, Ph.D. (University of California San Diego); Laura Campbell-Sills, Ph.D. (University of California San Diego); Catherine L. Dempsey, Ph.D., M.P.H. (Uniformed Services University of the Health Sciences); Richard Frank, Ph.D. (Harvard Medical School); Carol S. Fullerton, Ph.D. (Uniformed Services University of the Health Sciences); Nancy Gebler, M.A. (University of Michigan); Robert K. Gifford, Ph.D. (Uniformed Services University of the Health Sciences); Stephen E. Gilman, Sc.D. (Harvard School of Public Health); Marjan G. Holloway, Ph.D. (Uniformed Services University of the Health Sciences); Paul E. Hurwitz, M.P.H. (Uniformed Services University of the Health Sciences); Sonia Jain, Ph.D. (University of California San Diego); Tzu-Cheg Kao, Ph.D. (Uniformed Services University of the Health Sciences); Karestan C. Koenen, Ph.D. (Columbia University); Lisa Lewandowski-Romps, Ph.D. (University of Michigan); Holly Herberman Mash, Ph.D. (Uniformed Services University of the Health Sciences); James E. McCarroll, Ph.D., MPH (Uniformed Services University of the Health Sciences); Katie A. McLaughlin, Ph.D. (Harvard Medical School); James A. Naifeh, Ph.D. (Uniformed Services University of the Health Sciences); Matthew K. Nock, Ph.D. (Harvard University); Rema Raman, Ph.D. (University of California San Diego); Sherri Rose, Ph.D. (Harvard Medical School); Anthony Joseph Rosellini, Ph.D. (Harvard Medical School); Nancy A. Sampson, B.A. (Harvard Medical School); LCDR Patcho Santiago, M.D., M.P.H. (Uniformed Services University of the Health Sciences); Michaelle Scanlon, M.B.A. (National Institute of Mental Health); Jordan Smoller, M.D., Sc.D. (Harvard Medical School); Michael L. Thomas, Ph.D. (University of California San Diego); Patti L. Vegella, M.S., M.A. (Uniformed Services University of the Health Sciences); Christina Wassel, Ph.D. (University of Pittsburgh); and Alan M. Zaslavsky, Ph.D. (Harvard Medical School).

Contract grant sponsor: Department of the Army, U.S. Department of Health and Human Services, and NIH/NIMH; Contract grant number: U01MH087981.

\section{REFERENCES}

1. Nock MK, Deming CA, Fullerton CS, et al. Suicide among soldiers: a review of psychosocial risk and protective factors. Psychiatry. 2013; 76:97-125. [PubMed: 23631542]

2. Kessler RC, Colpe LJ, Fullerton CS, et al. Design of the Army Study to Assess Risk and Resilience in Servicemembers (Army STARRS). Int J Methods Psychiatr Res. 2013; 22:267-275. [PubMed: 24318217]

3. Nock MK, Stein MB, Heeringa SG, et al. Prevalence and correlates of suicidal behavior among soldiers: results from the Army Study to Assess Risk and Resilience in Servicemembers (Army STARRS). JAMA Psychiatry. 2014; 71:514-522. [PubMed: 24590178]

4. Joiner TE Jr. Conwell Y, Fitzpatrick KK, et al. Four studies on how past and current suicidality relate even when "everything but the kitchen sink" is covaried. J Abnorm Psychol. 2005; 114:291303. [PubMed: 15869359] 
5. Brown GK, Ten Have T, Henriques GR, et al. Cognitive therapy for the prevention of suicide attempts: a randomized controlled trial. J Am Med Assoc. 2005; 294:563-570.

6. Linehan MM, Comtois KA, Murray AM, et al. Two-year randomized controlled trial and follow-up of dialectical behavior therapy vs. therapy by experts for suicidal behaviors and borderline personality disorder. Arch Gen Psychiatry. 2006; 63:757-766. [PubMed: 16818865]

7. Rona RJ, Hyams KC, Wessely S. Screening for psychological illness in military personnel. J Am Med Assoc. 2005; 293:1257-1260.

8. Jones E, Hyams KC, Wessely S. Screening for vulnerability to psychological disorders in the military: an historical survey. J Med Screen. 2003; 10:40-46. [PubMed: 12790314]

9. Kessler RC, Heeringa SG, Colpe LJ, et al. Response bias, weighting adjustments, and design effects in the Army Study to Assess Risk and Resilience in Servicemembers (Army STARRS). Int J Methods Psychiatr Res. 2013; 22:288-302. [PubMed: 24318218]

10. Posner K, Brown GK, Stanley B, et al. The Columbia-Suicide Severity Rating Scale: initial validity and internal consistency findings from three multisite studies with adolescents and adults. Am J Psychiatry. 2011; 168:1266-1277. [PubMed: 22193671]

11. Kaplan EL, Meier P. Nonparametric estimation from incomplete observations. J Am Stat Assoc. 1958; 53:457-481.

12. Halli, SS.; Rao, KV. Advanced Techniques of Population Analysis. Plenum; New York, NY: 1992.

13. Efron B. Logistic regression, survival analysis, and the Kaplan-Meier curve. J Am Stat Assoc. 1988; 83:414-425.

14. Wolter, KM. Introduction to Variance Estimation. Springer-Verlag; New York, NY: 1985.

15. R Development Core Team. R: a language and environment for statistical computing. Vienna, Austria: R Foundation for Statistical Computing. 2011. Available at: http://www.R-project.org/

16. Lumley T. Survey: analysis of complex survey samples. R package version. 2011

17. Lumley T. Analysis of complex survey samples. J Stat Softw. 2004; 9:1-19.

18. Rosellini AJ, Heeringa SG, Stein MB, et al. Lifetime prevalence of DSM-IV mental disorders among new soldiers in the U.S. Army: results from the Army Study to Assess Risk and Resilience in Servicemembers (Army STARRS). Manuscript under review 2014.

19. Tourangeau R, Yan T. Sensitive questions in surveys. Psychol Bull. 2007; 133:859-883. [PubMed: 17723033]

20. Moffitt TE, Caspi A, Taylor A, et al. How common are common mental disorders? Evidence that lifetime prevalence rates are doubled by prospective versus retrospective ascertainment. Psychol Med. 2010; 40:899-909. [PubMed: 19719899]

21. Gadermann AM, Gilman SE, McLaughlin KA, et al. Projected rates of psychological disorders and suicidality among soldiers based on simulations of matched general population data. Mil Med. 2012; 177:1002-1010. [PubMed: 23025127]

22. Kessler RC, Borges G, Walters EE. Prevalence of and risk factors for lifetime suicide attempts in the National Comorbidity Survey. Arch Gen Psychiatry. 1999; 56:617-626. [PubMed: 10401507]

23. Nock MK, Borges G, Bromet EJ, et al. Cross-national prevalence and risk factors for suicidal ideation, plans, and attempts. Br J Psychiatry. 2008; 192:98-105. [PubMed: 18245022]

24. Nock MK, Green JG, Hwang I, et al. Prevalence, correlates, and treatment of lifetime suicidal behavior among adolescents: results from the national comorbidity survey replication adolescent supplement. JAMA Psychiatry. 2013; 70:300-310. [PubMed: 23303463]

25. Nock, MK.; Borges, G.; Ono, Y., editors. Suicide: Global Perspectives from the WHO World Mental Health Surveys. Cambridge University Press; New York, NY: 2012.

26. Gunnell D, Magnusson PK, Rasmussen F. Low intelligence test scores in 18 year old men and risk of suicide: cohort study. BMJ. 2005; 330:167-171. [PubMed: 15615767]

27. Jiang GX, Rasmussen F, Wasserman D. Short stature and poor psychological performance: risk factors for attempted suicide among Swedish male conscripts. Acta Psychiatr Scand. 1999; 100:433-440. [PubMed: 10626921]

28. Koenig HG. Religion, spirituality, and health: the research and clinical implications. ISRN Psychiatry. 2012; 2012 doi:10.5402/2012/278730. Available at: http://www.ncbi.nlm.nih.gov/pmc/ articles/PMC3671693/. 
29. Kleiman EM, Liu RT. Prospective prediction of suicide in a nationally representative sample: religious service attendance as a protective factor. Br J Psychiatry. 2014; 204:262-266. [PubMed: 24115346] 


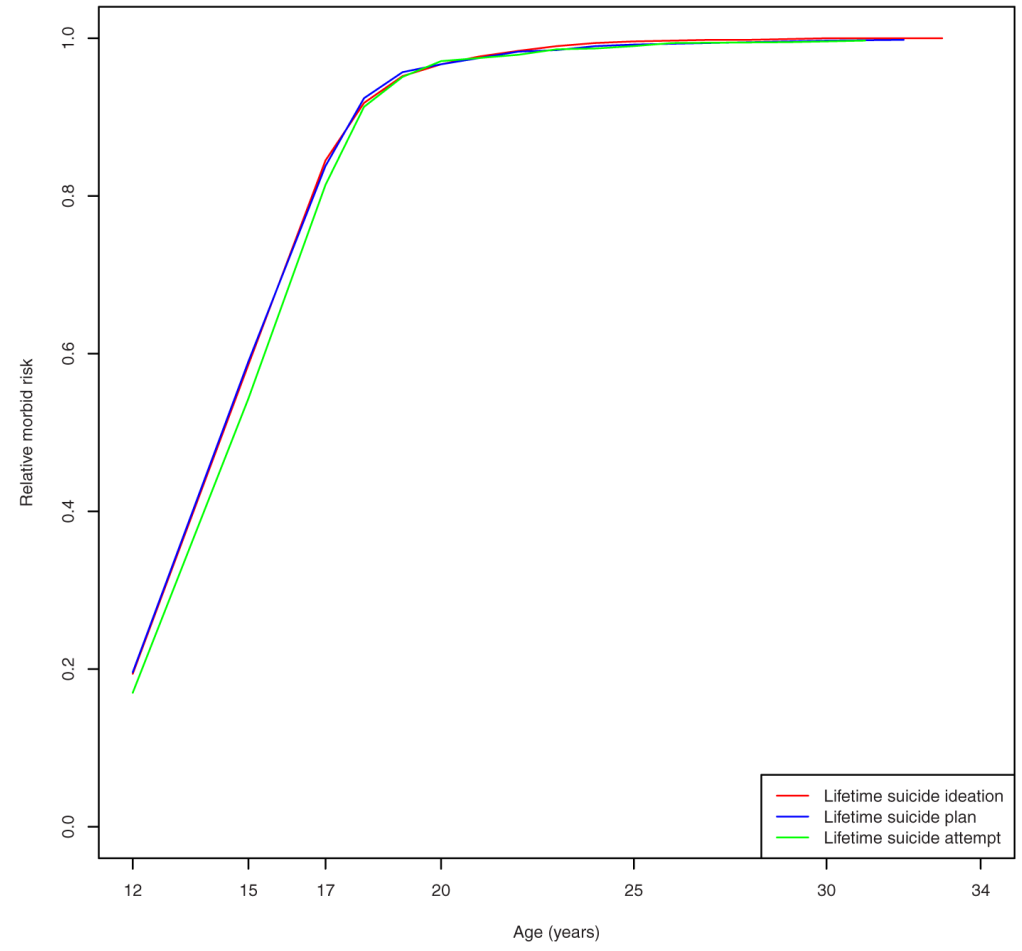

Figure 1.

Standardized AOO distributions of the preenlistment suicidal behaviors assessed in the Army STARRS NSS 


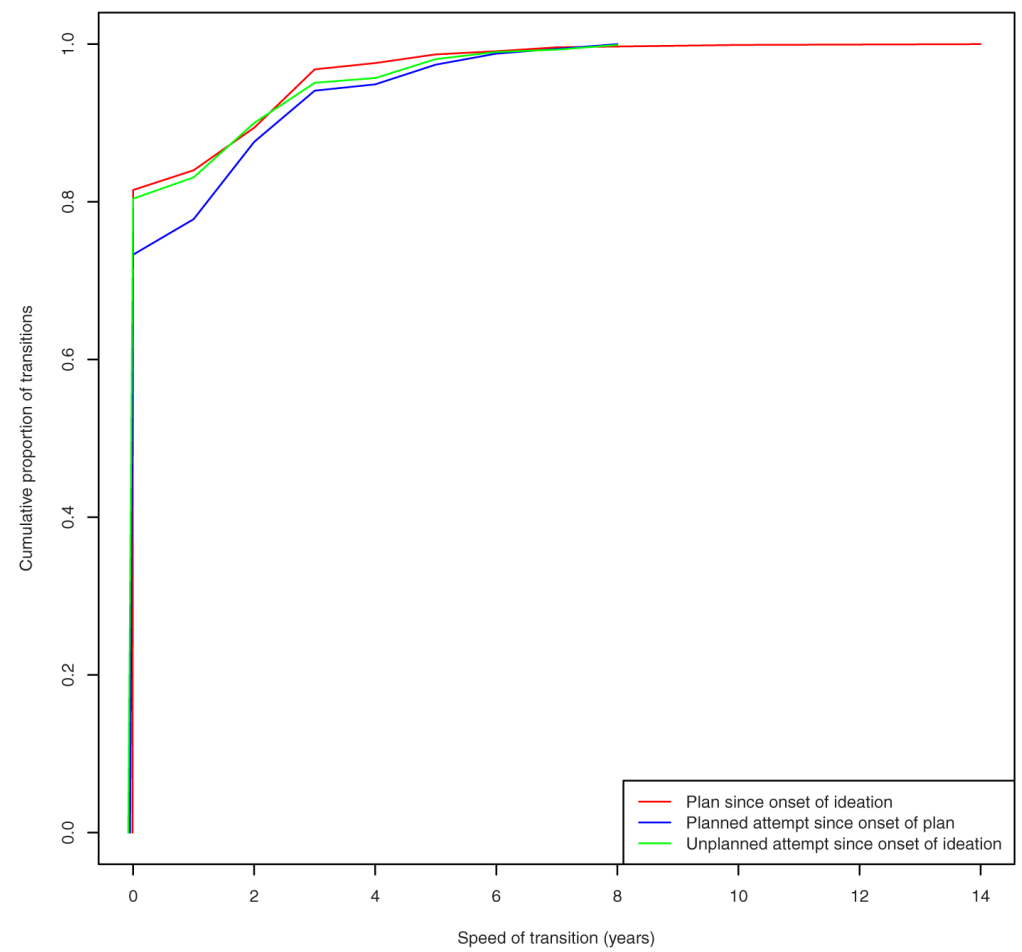

Figure 2.

Standardized speed of transition distributions in the transitions between first onsets of suicide ideation and plan, suicide plan and attempt, and ideation and unplanned attempt in the Army STARRS NSS 

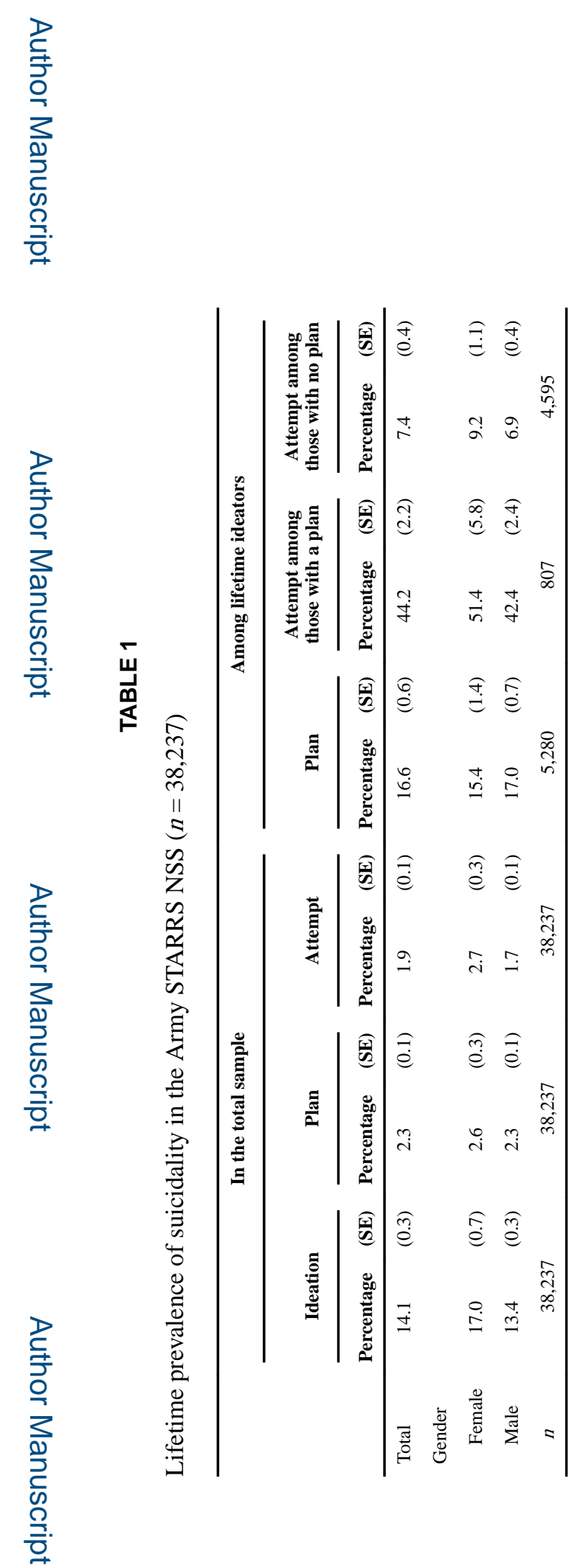

Depress Anxiety. Author manuscript; available in PMC 2016 November 17. 


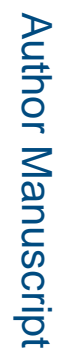

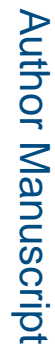

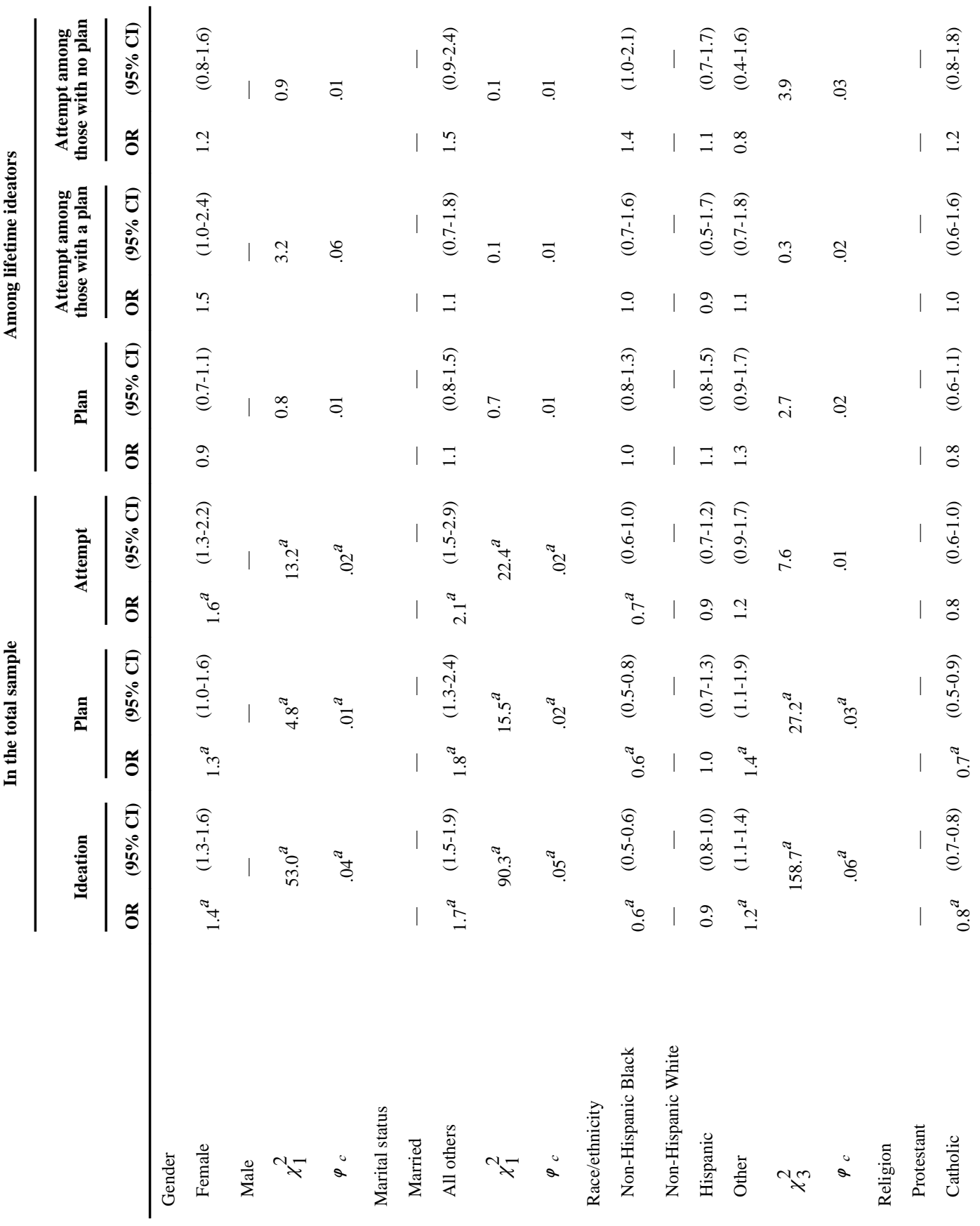

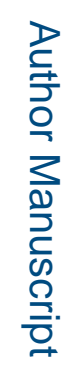

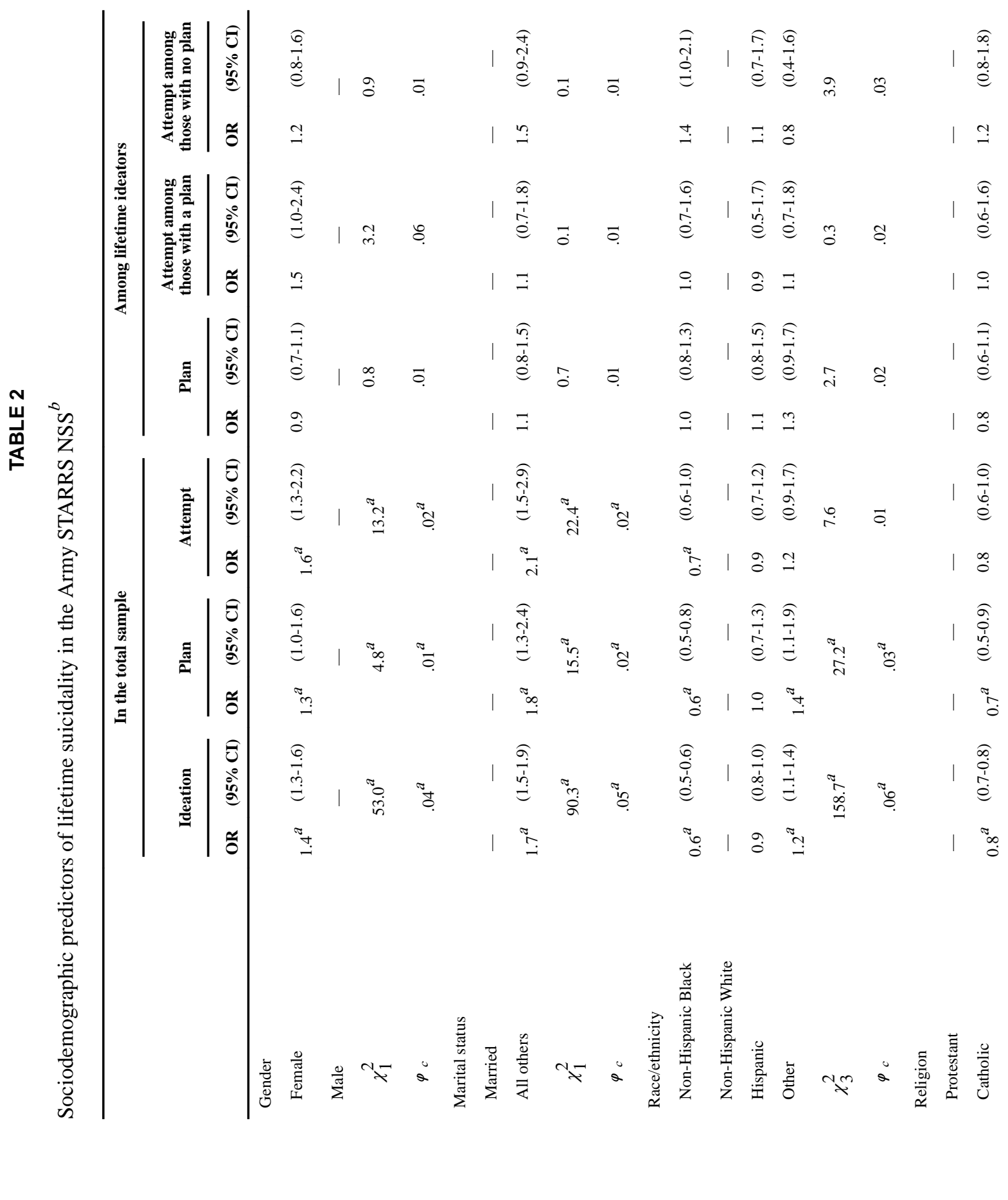

Depress Anxiety. Author manuscript; available in PMC 2016 November 17. 


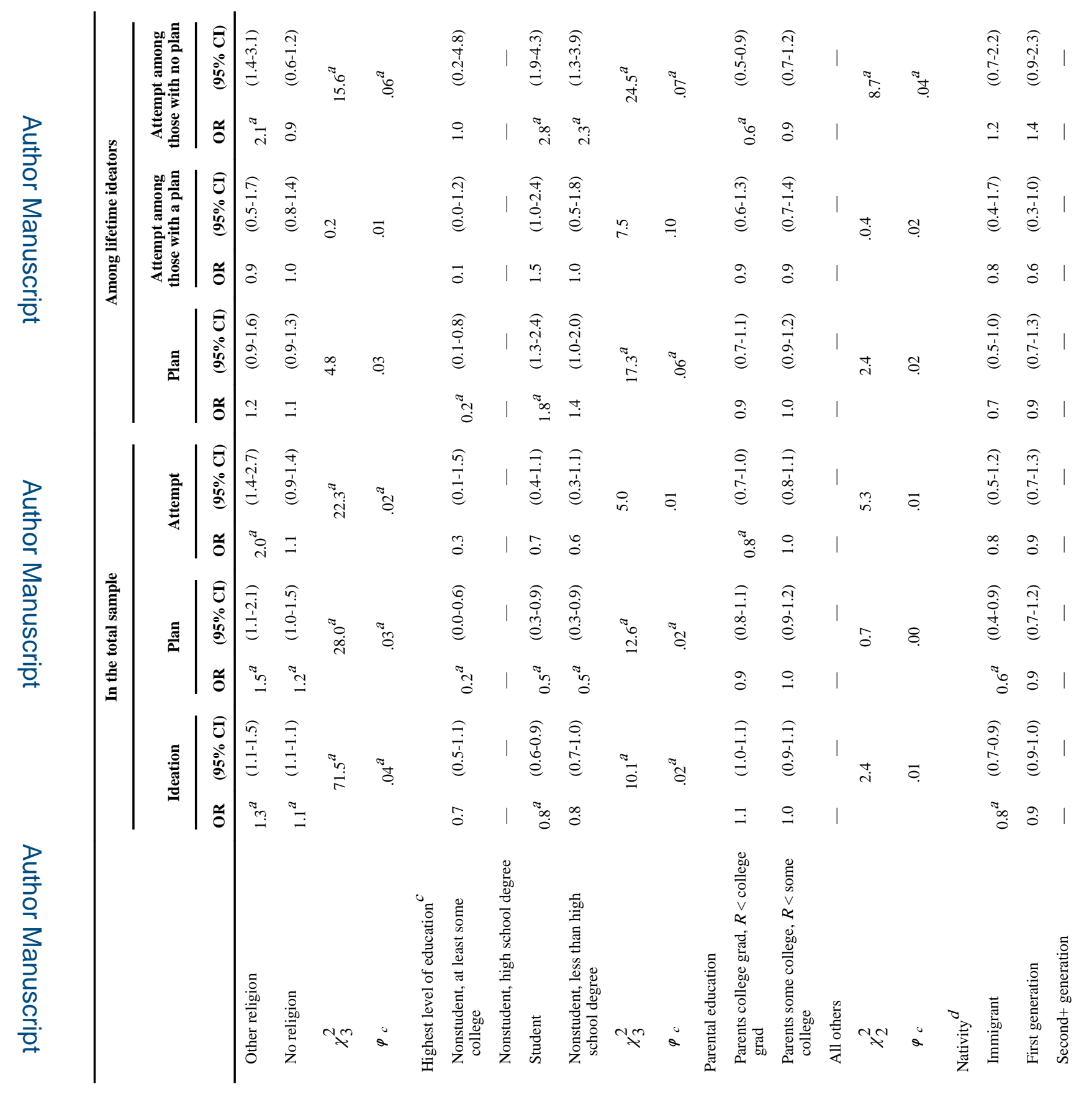

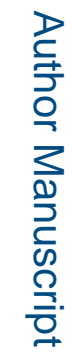

Depress Anxiety. Author manuscript; available in PMC 2016 November 17. 


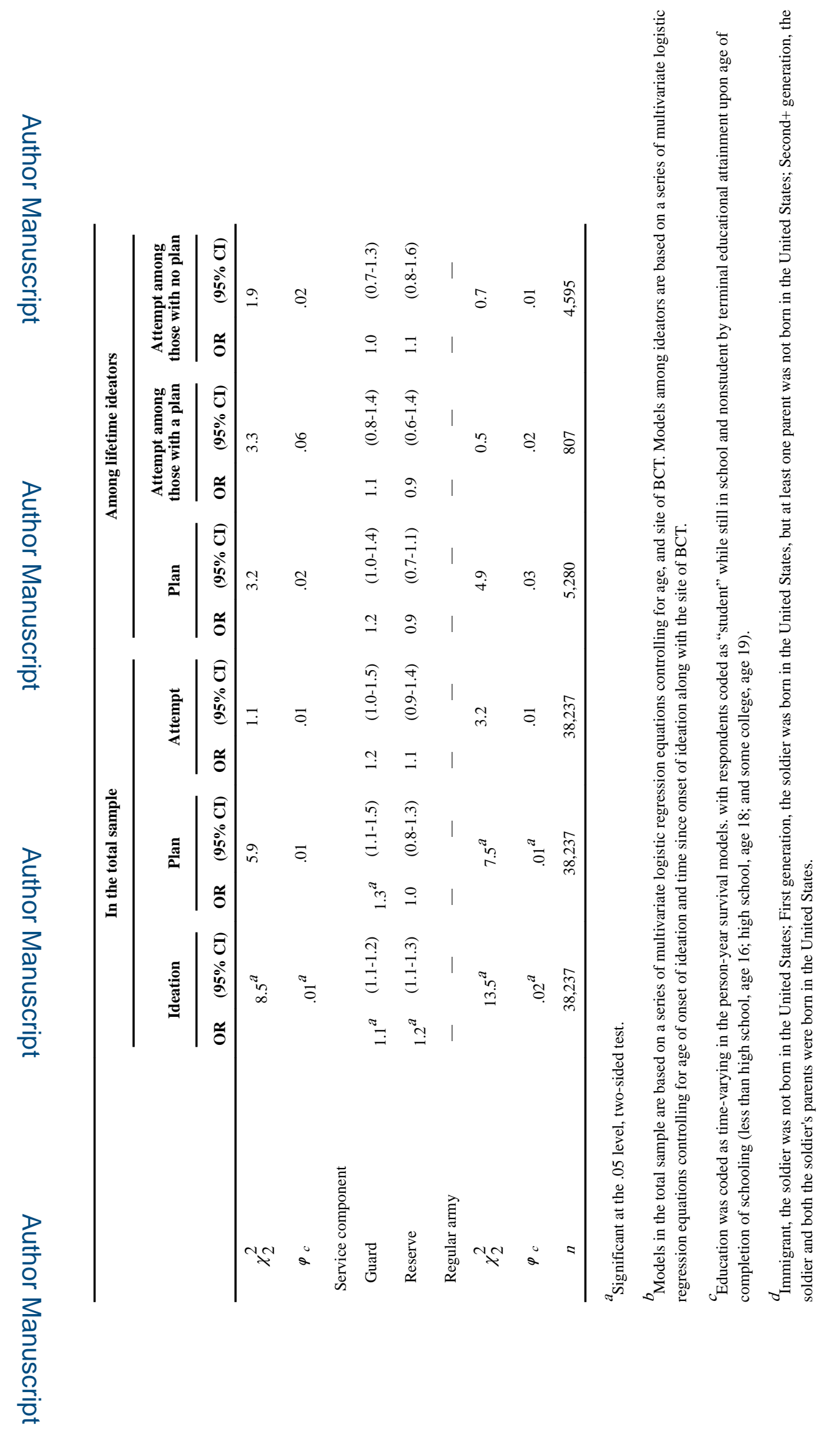

Depress Anxiety. Author manuscript; available in PMC 2016 November 17. 